REGARDS

SUR L'ECONOMIE ALLEMANDE

BULLETIN ECONOMIQUE DU CRAC

\section{Regards sur l'économie allemande}

Bulletin économique du CIRAC

$93 \mid 2009$

Varia

\title{
Innovation : les PME intensifient leurs efforts
}

\section{Solène Hazouard}

\section{OpenEdition}

Journals

Édition électronique

URL : http://journals.openedition.org/rea/3903

DOI : 10.4000/rea.3903

ISBN : 978-2-8218-0882-9

ISSN : 1965-0787

Éditeur

CIRAC

Édition imprimée

Date de publication : 1 octobre 2009

Pagination : 33-34

ISSN : 1156-8992

Référence électronique

Solène Hazouard, «Innovation : les PME intensifient leurs efforts", Regards sur l'économie allemande [En ligne], 93 I octobre 2009, mis en ligne le 01 octobre 2011, consulté le 15 septembre 2020. URL : http://journals.openedition.org/rea/3903

Ce document a été généré automatiquement le 15 septembre 2020

(C) CIRAC 


\title{
Innovation : les PME intensifient leurs efforts
}

\author{
Solène Hazouard
}

\section{$30 \%$ des PME innovent davantage}

1 Non moins de $30 \%$ des PME ont choisi d'accroître leurs efforts en matière d'innovation, contre seulement $17 \%$ des entreprises de plus de 1000 salariés. C'est ce qui ressort d'un sondage mené en juillet-août 2009 par la Confédération allemande des Chambres de Commerce et d'Industrie (DIHK) auprès de quelque 1100 entreprises innovantes. Les PME sont toutefois plus prudentes que lors de l'enquête DIHK-Innovationsreport 2008/2009, menée entre la mi-octobre et la fin novembre 2008 auprès d'un échantillon représentatif de 530 entreprises innovantes : 46,9\% d'entre elles souhaitaient alors étendre leurs efforts dans le domaine de l'innovation (voir REA 90/09). Cela étant, tandis que $18 \%$ des grandes entreprises freinent momentanément leurs activités innovantes pour des raisons financières, seules $5 \%$ des PME suivent cette stratégie elles savent que de leur capacité d'innovation dépendra leur compétitivité future.

\section{Malgré les aides octroyées dans le cadre du programme ZIM, ...}

2 L'enquête montre par ailleurs que le Programme central en faveur de l'innovation dans le Mittelstand (Zentrales Innovationsprogramm Mittelstand, ZIM), lancé le $1^{\text {er }}$ juillet 2008 par le gouvernement fédéral (il prend fin en 2013), est bien accepté par les entrepreneurs et constitue un facteur d'impulsion déterminant en termes d'innovation. D'approche pluridisciplinaire en matière de technologies et d'accès direct pour les entreprises, celui-ci s'est vu octroyer 900 millions $€$ supplémentaires dans le cadre des programmes conjoncturels du gouvernement fédéral, pour s'élever finalement à plus de 1,5 milliard $€$ sur la période 2009-2010. 


\section{...les PME peinent à financer leurs projets innovants}

Pourtant, les entreprises commencent à affronter un problème de financement : $16 \%$ d'entre elles se voient refuser un crédit pour mener à bien des projets innovants et $14 \%$ témoignent d'une situation financière difficile venant limiter leur capacité d'innovation. Cette situation touche tout particulièrement les start-up parmi les PME, dont les capacités d'autofinancement sont par définition limitées. Un tiers des entreprises sondées plaide dès lors en faveur d'une nouvelle série de mesures en matière de financement, tandis que $31 \%$ d'entre elles prônent un accès facilité aux aides sur projets accordées par les pouvoirs publics. En réponse, le ministère fédéral de l'Economie vient d'autoriser la banque publique $\mathrm{KfW}$ à prélever sur les 40 milliards $€ \mathrm{du}$ fonds spécial voté pour suppléer au crédit bancaire les moyens nécessaires pour octroyer des prêts globaux aux banques, afin d'accroître les possibilités de financement principalement des PME.

\section{Bureaucratie, fiscalité et main-d'œuvre qualifiée : trois enjeux clés}

4 Plus important, ce sont la réduction de la bureaucratie, la simplification du système fiscal et le recrutement plus aisé de main-d'œuvre qualifiée qui constituent toujours les revendications majeures de respectivement $58 \%, 54 \%$ et $40 \%$ des entreprises interrogées. "Des sujets à traiter en priorité lors de la nouvelle législature», en conclut le ministre de l'Economie sortant.

\section{Le savoir au cœur de tout processus innovant}

De son côté, le BMWi promeut le savoir via l'initiative " Fit für den Wissenswettbewerb " qui consacre depuis 2004 et jusqu'en 2012 une enveloppe de 17,5 millions $€$ au financement de plus de 34 projets, en vue de renforcer le management du savoir dans les entreprises du Mittelstand. Dans le cadre de cette initiative, 25 PME allemandes et suisses viennent d'être honorées du prix d'excellence 2009 des organisations du savoir "Exzellente Wissensorganisation ", parmi 50 entreprises initialement en lice. L'évaluation porte sur la capacité à générer durablement de la connaissance à l'échelle du management, des processus opérationnels et de la gestion de projets. Elle tient compte par ailleurs du savoir acquis par les collaborateurs et les partenaires extérieurs, avec pour visée d'identifier des solutions intégrées, transposables à d'autres entreprises, et de stimuler les échanges de bonnes pratiques, notamment au cours d'ateliers. (SH)

INDEX

Mots-clés : innovation, PME, Mittelstand, management, compétitivité, entreprise, financement 